\title{
En torno a la presunta oposición entre tiempo natural y tiempo histórico
}

\author{
Lucila Svampa
}

UBA / CONICET

\section{Los estratos, entre tiempo y espacio}

En la introducción a Zeitschichten, traducida al castellano por primera vez en el presente volumen de Prismas, Koselleck pone en movimiento conceptos centrales no solo para la historia conceptual, sino también relativos a su Theorie der geschichtlichen Zeiten (teoría de los tiempos históricos). Esta división aparece anunciada por él mismo en el texto para clarificar su preferencia editorial, en esta ocasión, por la teoría del tiempo en detrimento de su Begriffsgechichte. Y sin implicar ello que pueda trazarse una relativa independencia de un campo sobre el otro, este aviso deja planteado un terreno privilegiado sobre el cual se mueve y que excede pero también incumbe a las ciencias históricas. Es que Koselleck se ocupa aquí, entre otras cosas, de insistir sobre la calidad de indispensable que halla en la teoría del tiempo para cualquier práctica histórica, algo que desarrolla con gran virtud en el capítulo titulado "Über die Theoriebedürftigkeit der Geschichtswissenschaft". ${ }^{1}$ El hecho de que se ignore la necesidad de una explicitación de las condiciones de posibilidad de toda historia constituye un error garrafal, contra el que Koselleck dará pelea. Hay una exigencia de apertura de las disciplinas científicas con la que se debe saber lidiar y de la que la historiografía no puede evadirse. La historia se ve compelida a recurrir a conocimientos sociales, económicos y naturales para llevar adelante sus investigaciones. ${ }^{2} \mathrm{Y}$ esto

\footnotetext{
${ }^{1}$ Para una traducción al castellano de este capítulo véase Reinhart Koselleck, "Sobre la necesidad teórica de la ciencia histórica", Prismas, n 14, 2010, pp. 137-148. Muchos otros capítulos de este libro carecen, lamentablemente, de versión en castellano. La edición de Paidós reunió solo unos pocos textos de la compilación original. Véase Reinhart Koselleck, Los estratos del tiempo, Barcelona, Paidós, 2001. Otros capítulos fueron incluidos en otros ejemplares. Véase Reinhart Koselleck, Historias de conceptos, Madrid, Trotta, 2012; Reinhart Koselleck, Esbozos teóricos, Madrid, Escolar y Mayo, 2013; Reinhart Koselleck y Hans-Georg Gadamer, Historia y Hermenéutica, Barcelona, Paidós, 1997; Reinhart Koselleck, Modernidad, culto a la muerte y memoria nacional, Madrid, Centro de estudios políticos y constitucionales, 2011; Josetxo Beriain y Maya Aguiluz (eds.), Las contradicciones culturales de la modernidad, Madrid, Anthropos, 2007.

${ }^{2}$ Esta idea aparece también con mucha fuerza en algunos capítulos de Vom Sinn und Unsinn der Geschichte, como en "Interdisziplinäre Forschung und Geschichtswissenschaft" y "Wozunoch Historie?". En este último texto, el escritor apunta: "la ciencia histórica depende por su parte del proceso de articulación sistemática de las ciencias sociales en su conjunto”. Reinhart Koselleck, “¿Para qué todavía una investigación histórica?” En Sentido y repetición en la historia, Buenos Aires, Hydra, 2013, p. 61. Esto ha tenido un desarrollo teórico y un consabido correlato institucional. En efecto, Koselleck promovió la interdisciplinariedad respaldándose en la difusión de resultados de investigación en revistas científicas, que supieron hacerse a un lado de las tendencias al aislamiento, como History and
} 
no constituye una debilidad de esa ciencia en relación a otras. Tampoco implica que deba jugar un papel de "auxiliar" -mucho menos una jerarquización disciplinar-, sino que señala una inevitable interdependencia entre todas ellas. Hay un obligado mestizaje científico que es reivindicado por Koselleck como un lugar de pertenencia. A esto se le suma una convergencia entre lo histórico y lo metahistórico, que protagonizarán, en gran medida, discusiones centrales que Koselleck enuncia en estas páginas introductorias y sobre la que vuelve en más de un capítulo. Con dicho propósito, el padre de la historia conceptual apunta a la necesidad del uso de metáforas espaciales. Así lo señala en uno de los capítulos más centrales del libro:

La historia [Historie] como ciencia vive, a diferencia de otras ciencias, solo de metáforas. Esta es, en cierto modo, nuestra premisa antropológica, puesto que todo lo que quiere ser formulado temporalmente tiene que apoyarse en el sustrato sensible de la intuición empírica. La pérdida de intuición del tiempo puro nos conduce al centro de las dificultades metódicas sobre poder construir de alguna manera proposiciones sensatas sobre una teoría de los tiempos históricos en general. ${ }^{3}$

No es posible, por ende, una historia autosuficiente que prescinda de recursos provistos por otros terrenos disciplinares. Y tal peculiaridad se explica porque la historicidad se ancla, indefectiblemente, en una temporalidad que no puede asirse sino mediante una base empírica, que la vuelva perceptible.

Mas en el uso de metáforas y conceptos ajenos a la ciencia histórica habrá que recordar que Koselleck no es un pionero. Se remite, de hecho, a una práctica que se vuelve válida en torno al siglo XVIII y en este contexto cita a Kant, específicamente a Allgemeine Naturgeschichte und Theorie des Himmels. Allí el filósofo de Königsberg hace referencia a "ganze Gebürge von Millionen Jahrhunderten" (montañas enteras de millones de siglos) para referirse a los enormes cambios que atraviesa la naturaleza -también aparecen entre sus referencias Carl Gustav Carus y Joseph Görres-- ${ }^{4}$ Tampoco es Koselleck el único en volver sobre su uso dos siglos después: la expresión estratificación social forma parte de una terminología sociológica muy corriente. Por su parte, acaso el vocabulario meteorológico con el que Walter Benjamin homologa progreso y catástrofe sea uno de los más reconocidos y agudamente descriptivos en la crítica a la linealidad dentro de la filosofía de la historia. Imposible es obviar, al mismo tiempo, todo el trabajo de Hans Blumemberg sobre la metaforología. ${ }^{5}$ En fin, en la obligación de asumir que a la historia el tiempo se le escapa, por decirlo de algún modo, está asimismo presente el deber de apelar a una exterioridad que dé cuerpo al tiempo.

Theory, en reuniones y eventos organizados por círculos de especialistas de varias disciplinas, como Poetik und Hermeneutik y, además, en la creación del Zentrum für Interdisziplinäre Forschung, en la Universidad de Bielefeld.

${ }^{3}$ R. Koselleck, Sobre la necesidad, p. 142.

${ }^{4}$ Faustino Oncina Coves recuerda que Vico representa un antecedente importante en este sentido. Véase Faustino Oncina Coves, "Introducción” a F. Oncina Coves y P. García Durán (comps.), Historia in/conceptual y metaforología: método y modernidad, Valencia, Pre-textos, 2015. Para más precisiones sobre el uso de las metáforas en Koselleck, véase también Falko Schmieder, "Geschichtsmetaphern und ihre Geschichte. Eine Auseinandersetzung mit Reinhart Koselleck”, Forum Interdisziplinäre Begriffsgeschichte (FIB), 10, 2021, pp. 25-38.

${ }^{5}$ Hans Blumemberg, Paradigmas para una metaforología, Madrid, Trotta, 2003. Hay un instructivo comentario sobre el tema en Elías José Palti, "Ideas, conceptos, metáforas. La tradición alemana de historia intelectual y el complejo entramado del lenguaje”, Res publica, 25, 2011, pp. 227-248. 
Las figuras espaciales proporcionan la ventaja de captar simbólicamente fenómenos que van más allá de los conceptos e incluso del término Schichten (estratos): Koselleck designa en su obra muchas otras voces con connotaciones espaciales, a saber: Standortbidung (conexión con la ubicación), Utopie (utopía), Erfahrungsraum (espacio de experiencias) y Erwartungshorizont (horizonte de expectativas), entre otros. En este contexto, conceptos como los de "estratos", "fricciones" o "fracturas" del tiempo logran dar fehacientemente con densidades temporales que permiten marcar ritmos y niveles en que se manifiestan dimensiones diversas de la experiencia. Podríamos sintetizar este movimiento en tres puntos: en primer lugar, Koselleck catapulta la interdisciplinariedad de los campos científicos; en segundo lugar, evoca metáforas geológicas aludiendo a una necesidad de importar conceptos que tengan un respaldo sensible; y en tercer lugar, respondiendo a las necesidades inscriptas en su crítica a la linealidad no emplea cualquier tipo de metáforas geológicas. Excluye aquellas que refieran a una sucesión lineal, como "llanura" o "planicie"; muy por el contrario, sugiere figuras que muestren diversas profundidades de un tiempo múltiple.

El uso de estas metáforas se vuelve central a la hora de examinar el tiempo, que solo se deja comprender sobre la base de imágenes espaciales. Hay una operación semántica que traslada un término de otra área de estudios, en principio ajena, para volver el fenómeno temporal inteligible. Con tal fin, debemos emplear un geschichtliche Bewegungskoeffizienten (coeficiente de movilidad histórica), que nos permita aprovechar los aportes de ciencias vecinas en el acercamiento a fenómenos históricos. ${ }^{6}$ A Koselleck le interesa especialmente remitirse a la geología para esquivar el dilema entre circularidad y linealidad y gracias a los Zeitschichten (estratos de tiempo), registra tanto la Einmailigkeit (unicidad) como las Wiederholenstrukturen (estructuras de repetición). Estas últimas reconocen la iterabilidad que domina la vida de los hombres sin impedir la llegada de novedades. Se trata de estructuras que controlan las recurrencias en distintos ámbitos culturales, como el biológico, el jurídico, el lingüístico, el económico a los que Koselleck añade los estratos, que enmarcan todos los acontecimientos singulares. Se habilita así un análisis que contempla movimientos, coincidencias e incluso desfasajes que explican cómo algunos fenómenos alcanzan un curso temporal similar por un tiempo y luego se desvían a partir de aceleraciones o ralentizaciones, dando lugar así a nuevas formaciones o recomponiendo en una misma instancia temporal lo otrora diverso. Este esquema, que permite identificar interrupciones espacio-temporales, depende, stricto sensu, de un rechazo del vector del progreso, que se proyecta sobre la base de una linealidad y de una concepción homogénea del tiempo.

Este modo de comprender la temporalidad en su multiplicidad tiene un impacto, desde luego, en la historicidad. Las aproximaciones a la historia que se construyen sobre la base de una orientación teleológica serán profundamente desacreditadas por Koselleck, quien lanza una crítica, entre otros puntos, desde la negación de la existencia de un sentido al que tienda el desarrollo histórico y, por ende, de una concordancia en la interpretación de los hechos que los una en una concatenación coherente. En efecto, desplazar la discusión del sentido a la del uso es un primer movimiento que emprende Nietzsche en el siglo XIX y cuyo guante recogerá Koselleck, a través de una lectura crítica de la segunda de las intempestivas. ${ }^{7}$ Esto se refleja en

\footnotetext{
${ }^{6}$ Koselleck, “¿Para qué?”, p. 71.

${ }^{7}$ Según su lectura, Nietzsche invirtió la fórmula historia magistra vitae por historia ancilla vitae pero reemplazó el problema del sentido por el de la vida. Al justificar los modos de usar la historia en beneficio de la vida, cayó en una nueva ambigüedad. Véase Friedrich Nietzsche, Sobre utilidad y perjuicio de la historia para la vida, Madrid, Biblioteca Nueva, 2003.
} 
su preferencia por el término Sinnlosigkeit (ausencia de sentido) sobre el de Unsinn (sin sentido) como reacción a las filosofías de la historia adeptas al progreso. ${ }^{8}$

Tiempo y espacio son, ciertamente, para Koselleck, una condición de posibilidad de la historia. La herencia kantiana establece que, en tanto intuiciones puras, se trata de representaciones que, sin embargo, gozan tanto de idealidad trascendental como de realidad empírica. ${ }^{9} \mathrm{El}$ espacio como "la condición subjetiva de la sensibilidad" interviene en la intuición de las cosas. De un espacio concebido como a priori se deriva la naturaleza pura y aplicada de la geometría, que menciona Kant, pero veremos que también el carácter práctico de la historiografía. ${ }^{10}$ En el capítulo de Zeitschichten titulado "Raumund Geschichte", Koselleck observa una serie de ambigüedades planteadas en la relación de espacio y tiempo. Este último será concebido de diferentes modos a través de la historia y es incluso posible registrar la convivencia de una diversidad de concepciones en un mismo momento histórico. Pero Koselleck agrega que el espacio es una categoría también histórica, es decir, sujeta a cambios e influida por condiciones políticas, económicas y sociales. Hay una suerte de bipolaridad que revela un movimiento pendular entre las condiciones metahistóricas geográficas y naturales de existencia y los espacios creados por el hombre. El límite entre aquello que está al alcance del dominio humano o no también estará sujeto, en definitiva, a cambios históricos. Podríamos decir, con Schmitt -a quien, por cierto, Koselleck no cita en este capítulo pero cuya herencia se deja ver de forma patente-, que acaso esa diferencia coincide con aquello que puede ser tomado o no, si se parte de la idea de un nomos que nos permite avanzar sobre ciertos espacios. ${ }^{11}$ Esto señala, a todas luces, una gran relevancia geopolítica y contempla también transformaciones históricas que muestran la paulatina apropiación que el hombre ha hecho de la tierra, el agua y el aire.

Lo anterior se traduce en una conquista progresiva de las condiciones naturales, o lo que es lo mismo que decir en una transformación de las condiciones metahistóricas en históricas. También nos interpela actualmente desde preocupaciones socioambientales sobre las que la humanidad influye y que la puede arrastrar a una máxima catástrofe. A esto se agrega que el estado crítico en términos ecológicos de las condiciones de vida que determinan el espacio en que la historia tiene lugar traspasa las fronteras locales y se ubica en un plano global, en el que la toma de decisiones se complejiza. Que lo metahistórico puede determinar lo histórico y lo histórico lo metahistórico se hace cada vez más evidente, sobre todo si adoptamos una perspectiva de largo plazo. Las mutaciones que sufren las relaciones entre espacio y tiempo no pueden, asimismo, ignorar el desarrollo de las comunicaciones, el despliegue tecnológico y el acortamiento del tiempo de los viajes, junto con el fenómeno de la aceleración, que es caracterizado por Koselleck en una tercera curva de tiempo.

\footnotetext{
${ }^{8}$ Las adjudicaciones de sentido en interpretaciones retrospectivas le resultan, sin más, macabras. Sin embargo, la ausencia de sentido no debe confundirse con la promoción de un nihilismo. Reinhart Koselleck, Vom Sinn und Unsinn der Geschichte, Frankfurt, Suhrkamp, 2013. Véase también sobre este tema Jan Eike Dunkhase, Absurde Geschichte. Reinhart Koselleckshistorischer Existentialismus, Marbach am Neckar, Deutsche Schillerges, 2015.

${ }^{9}$ Immanuel Kant, Crítica de la razón pura, Buenos Aires, Losada, 2003, pp. 195-223.

${ }^{10}$ Mientras que el espacio se refiere al sentido externo, el tiempo lo hace al sentido interno. En tanto solo podemos emplear espacio y tiempo a aquello de lo que tenemos intuiciones de los fenómenos del mundo empírico ¿cómo temporalizar entonces la historia, concebida como una idea, según la perspectiva kantiana? Chignola ofrece un comentario sobre este tema, a propósito de la recepción koselleckiana de Kant. Véase Sandro Chignola, "Temporalizar La Historia. Sobre la Historik de Reinhart Koselleck”, Isegoría, n 37, 30 de diciembre de 2007, pp. 11-33.

${ }^{11}$ La tierra firme, en oposición al mar libre, se puede tomar, partir y apacentar, Carl Schmitt, El nomos de la tierra en el derecho de gentes del Jus publicum europaeum, Buenos Aires, Struhart, 2005.
} 


\section{El rol de la Gleichzeitigkeit des Ungleichzeitigen y la contienda entre tiempo natural e histórico}

Puede arriesgarse, no con gran ventura, una sinonimia entre la metáfora de los estratos del tiempo y lo no contemporáneo. A pesar de que la importancia de lo anacrónico puede rastrearse en gran parte de la obra de Koselleck, en la introducción a Zeitschichten tal afinidad se revela a las claras cuando dice que die Gleichzeitigkeit des Ungleichzeitigen permite una coexistencia de eventos surgidos en distintos momentos cronológicos. Esto también se menciona en un capítulo dedicado a la Zeitgeschichte (historia del tiempo presente), en el que propone pensar en formas caleidoscópicas, considerando múltiples combinaciones entre pasado, presente y futuro, capaces de desdibujar las fronteras entre las dimensiones temporales:

Hay constelaciones repetibles, efectos a largo plazo, actitudes arcaicas que perviven, regularidades en la serie de los acontecimientos, acerca de cuya actualidad un historiador del tiempo presente puede informarse a partir de la historia. Y es que, como se dijo, la historia del tiempo presente, elevada a la categoría de concepto, es más que la historia de nuestro presente. Solo cuando sabemos lo que se puede repetir en cualquier momento, aunque no siempre igual, podemos ponderar lo que hay realmente de nuevo en nuestro tiempo. Tal vez menos de lo que solemos suponer. ${ }^{12}$

Pero este concepto aparece con fuerza ya en escritos previos. ${ }^{13}$ En Vergangene Zukunft, Koselleck apunta en el primer capítulo a un análisis del Alexanderschlacht de Altdorfer, para señalar la contemporaneidad de los turcos que asediaron a Viena en 1529 con el ejército persa, vencido por Alejandro Magno en el 333 a.c. en la batalla de Issus. De este modo, muestra cómo dos eventos distanciados por casi dos milenios encontraban una confluencia temporal al desafiar la cronología lineal. ${ }^{14} \mathrm{El}$ artista recurre a distintos elementos para recrear esa no contemporaneidad, plasmados en detalles del fresco que están fuera de su tiempo, es decir, que le son inactuales. El anacronismo al que se refiere no constituye en absoluto un error metodológico o un descuido, sino que es una estrategia estético-política. Hay una clara contemporaneidad entre el suceso de la antigüedad retratado y el ataque infructuoso de los turcos a Viena. Esto hace evidente que la no coincidencia con el tiempo calendario no imposibilita que dos eventos se perciban como contemporáneos, pues se trata de modos de poner en paralelo acontecimientos separados por umbrales epocales.

Aun así, sabemos que se volvería problemático no contar con divisiones que ordenen los eventos en el tiempo. En respuesta a esto, hay una interesante polémica sobre si existe o no una teoría de la periodización en Koselleck. ${ }^{15}$ Predomina una ambigüedad en su mirada porque, por un lado, encontramos un trabajo sistemático de su parte sobre el inicio de la modernidad, que depende de un momento bisagra, capturado a través del Sattelzeit. De hecho, toda la empresa intelectual de Koselleck en torno a la historia conceptual obedece a ese momento, que fecha

\footnotetext{
${ }^{12}$ Koselleck, Los estratos, p.133.

${ }^{13}$ En efecto, el primer capítulo de Vergangene Zukunft al que aquí aludimos data de 1968. Véase Reinhart Koselleck, "Vergangene Zukunft der frühen Neuzeit", en H. Barion, E.-W. Böckenförde, E. Forsthoff y W. Weber (comps.), Epirrhosis, Festgabe für Carl Schmitt, Berlín, Duncker und Humblot, 1968, pp. 549-566.

${ }^{14}$ Esto le permite a Koselleck afirmar que aquí se funden Historie y Geschichte. Véase Reinhart Koselleck, historia/ Historia, Madrid, Trotta, 2010.

${ }^{15}$ Este debate es sintetizado por el noruego Helgue Jordheim. Véase Helgue Jordheim, AGAINst Periodization: Koselleck's Theory of Multiple Temporalities, History and Theory, 51, mayo de 2012), pp. 151-171.
} 
entre 1750 y 1850 , cuando se producen una serie de transformaciones en la vida de los conceptos (se temporalizan, se politizan, se ideologizan y se democratizan). Pero, por otro lado, sabemos que Koselleck apela a la sincronía de eventos distanciados cronológicamente. Y esto último solo puede señalarse si se desafía la linealidad del tiempo y no se lo concibe como un todo homogéneo, cuantificable de manera estable. A su vez, para declarar la existencia de anacronismos, debemos apoyarnos en periodicidades, lo que nos reenvía hacia la conformación de una aporía. En otras palabras: no podemos identificar la contemporaneidad de lo no contemporáneo sin la presencia de fronteras que dividan épocas. Estas proveen la facultad de establecer períodos que agrupan características comunes en términos políticos, económicos o sociales. Pero mientras que el leitmotiv de estos contornos temporales es marcar diferencias entre distintos momentos históricos, con la idea de una simultaneidad de lo no simultáneo, esos umbrales se volverían en contra de sí mismos. Sin embargo, tal oposición no parece ser absoluta, en el sentido de que no necesariamente implica una contradicción. Incluso podríamos decir que la contemporaneidad de lo no contemporáneo presupone una división epocal basada en la linealidad cronológica. Ella se apoya indefectiblemente en un antes y un después, propios de una narración basada en un transcurso lineal del tiempo. Hay una necesidad de crear y remitirnos siempre a una cronología natural que hace que nos movamos entre ella, la separación de épocas basadas en una cronología histórica y la negación de estas dos, a partir de la contemporaneidad de lo no contemporáneo.

De modo que en cuanto a las disquisiciones sobre el tiempo histórico, encontramos tanto una apelación a una continuidad, como un pedido de la anulación de las fronteras por ella presupuestas, que evade un reconocimiento de su verdadera complementariedad. En pocas palabras, aquí Koselleck no termina de resolver una oposición que convive en tensión con una dependencia entre ambos registros, es decir, procede a medias tintas. Posiblemente esta vaguedad repose en su imposibilidad de asumir que su modo de concebir la tarea del historiador requerirá siempre de un tiempo cronológico en el que apoyarse para poder narrar. Extremado este razonamiento, podríamos aseverar que es indiferente si una narración se ajusta o se distancia de la escala lineal, porque la sujeción a la cronología es invariable. La cuestión no se define, por ende, en torno a cuántos anacronismos podríamos determinar o permitir, ni en función de cuánta distancia temporal separa los hechos que ponemos en paralelo -y vuelve esa operación acaso más osada, o, cuanto menos, inesperada- sino en que esa simultaneidad de no lo simultáneo se construye sobre la base de una cronología que al mismo tiempo transgrede, pero que la hace posible. Se trata, en definitiva, de procurar la supervivencia de un orden historiográfico, con el que Koselleck se enfrenta pero del que sigue formando parte.

De este modo se pone de manifiesto la inevitabilidad de lo no contemporáneo como eje que relativiza pero también depende de la fijeza de las unidades temporales, ya que solo podemos identificar desajustes temporales si partimos de continuidades. Sin duda, la importancia de las relaciones de lo diacrónico con lo sincrónico, rastreable no solo en representaciones estéticas, sino además en registros archivísticos, en los conceptos mismos y en el interior de realidades geográficas - que apuntan a la figura del anacronismo- ilumina la simultaneidad que puede unir eventos separados por gran distancia temporal pero en más de una dirección. ${ }^{16}$ Este modo de leer

\footnotetext{
${ }^{16}$ Los factores sincrónicos y los efectos diacrónicos de la guerra en la conciencia de los alemanes son estudiados por Koselleck en el capítulo titulado "Erinnerungsschleusen und Erfahrungsschichten. Der Einfluß der beiden Weltkriegeauf das soziale Bewußtsein”. Allí hay un análisis de las vivencias anteriores, simultáneas y posteriores a la guerra.
} 
los acontecimientos acoge interrupciones en dos sentidos: hacia atrás, en tanto nos permite invocar la permanencia de eventos que cronológicamente se ubican en el pasado, y hacia adelante, en tanto nos habilita a producir enunciados intempestivos, que refieren a un tiempo que aún no se experimenta sino como una anticipación que contiene deseos o conjeturas. A esto, en parte, correspondería aquello que Koselleck caracteriza como lo que llega demasiado temprano o demasiado tarde y que puede cristalizarse en estandarizaciones políticas que dividen el globo según el ritmo de su desarrollo. ${ }^{17}$ De ello se deduce, en primer lugar, que die Ungleichzeitige tiende a la prognosis en tanto evoca modos de reapariciones o repeticiones del pasado en el futuro. De hecho, Koselleck señala que el componente más importante para la prognosis es el recuerdo, en tanto conlleva la expectativa de una repetición. Es por eso que desprovistos de repeticiones, estaremos asimismo desprovistos de futuros proyectables en forma de vaticinios. Pero sería problemático que, a partir de allí, se deduzca que todo devenir histórico recrea de forma idéntica lo ya sucedido o que es cautivo de esas estructuras. Por una parte, estas últimas pueden variar a través del tiempo y, por otro lado, es posible pensar en eventos extraordinarios que no se dejan clasificar bajo la égida de una estructura de repetición, pero que acaso formen parte de estructuras incipientes -y por ende aún no consolidadas-, cuya validez, en todo caso, pueda corroborarse ex post.

La tarea del historiador girará en torno a su capacidad de registrar y trazar estas estructuras, teniendo en cuenta distintas densidades y velocidades para su comportamiento. Podría objetarse, empero, que este modelo epistemológico anula la emergencia de una singularidad pura, en tanto toda particularidad estará compelida a entrar en una comparación con otras. Además, implicaría sustraerle al agente toda capacidad de acción sobre la Verfügbarkeit (disponibilidad) de la historia. ${ }^{18}$ Sin embargo, lo que Koselleck indica con esta construcción es que más allá de los proyectos utópicos que puedan existir o de la irrupción de lo inesperado, no existen eventos por fuera de la historia, esto es, se trata de estudiar las condiciones de posibilidad de la historia, algo que, mayormente, se alcanza con un análisis de las estructuras de repetición. En segundo lugar, se puede ver que los parámetros antes referidos -adelante y atrás-, útiles para ordenar los acontecimientos, no quedan exactamente vetustos pero sí obligan a reformular su rol privilegiado y estático en la conformación de la narración histórica.

En el capítulo titulado "Die unbekannte Zukunft und die Kunst der Prognose" Koselleck pone en el centro la cuestión del futuro. Allí nuevamente se remite a Kant, en la búsqueda de un "arte de la prognosis" y advierte, inicialmente, una marcada diferencia entre pasado y futuro, definida por la posibilidad de experimentar el primero pero no el segundo. ${ }^{19}$ A pesar de ello, Koselleck es cauto en esta distinción y agrega que, en definitiva, el futuro impacta sobre el curso del presente y sobre los modos en que revisamos el pasado y, por tanto, también se experimenta. ${ }^{20}$ No obstante, hay una preeminencia del tiempo natural sobre el histórico, que deja a este en las sombras de aquel. Si unas líneas más arriba destacábamos la diferencia entre tiempo cronoló-

\footnotetext{
${ }^{17}$ Koselleck se refiere a Alemania como una nación atrasada o tardía, a la luz de una discusión que entabla con Helmuth Plessner en relación con el proceso y los tiempos de su unificación.

${ }^{18}$ Reinhart Koselleck, Futuro Pasado, Madrid, Paidós, 1993.

${ }^{19}$ Véase Immanuel Kant, Antropología en sentido pragmático, Buenos Aires, Losada, 2010.

${ }^{20}$ Esto es denominado como una "Antinomie der Geschichte" (antinomia de la historia): "El pasado es absolutamente pasado, es irrevocable -y al mismo tiempo no lo es-: el pasado es presente y contiene futuro. Restringe posibilidades venideras y genera otras, está dado en nuestro lenguaje, está grabado en nuestra conciencia y en el inconsciente, así como en nuestras formas de comportamiento. Está inscripto tanto en nuestra instituciones como en la crítica de las mismas”. Koselleck, “¿Para qué”, p. 68.
} 
gico y tiempo histórico, aquí se trata de marcar la distancia entre el tiempo natural y el tiempo histórico. Koselleck se apoya en Kant para volver sobre la pretensión de una cronología que se base en la historia -y no viceversa-. ${ }^{21}$ Las unidades temporales con las que contamos el paso del tiempo -días, meses, años- son ciclos dependientes de condiciones cosmológicas dadas, que forman parte de las estructuras de repetición concernientes a lo außermenschliche (extrahumano). Estas proporcionan la estabilidad característica de los movimientos constantes del cosmos y constituyen precondiciones naturales de existencia de los hombres y que, nolens volens, dan orden a nuestra cotidianeidad. Póngase el simple ejemplo de la incidencia del Sol sobre la Tierra, parámetro indiscutido para marcar la diferencia entre la noche y el día y que organiza desde el sueño y la vigilia hasta nuestra dieta, actividades laborales, educativas y recreativas.

La constancia del espacio y del tiempo sideral no es, empero, inalterable. A prima facie, los movimientos de los cuerpos celestes constituyen propiedades externas a la historia de la humanidad, dado que difícilmente podamos influir en su curso. Esta eventualidad ocurriría si ingresase dentro de las condiciones históricas modificables a las que nos referíamos en el primer apartado. A esto se le suma que nada indica que la lectura que hagamos de dichos fenómenos sea necesaria. Y más allá de que las variables naturales tengan una vida independiente de nuestra aproximación científica, esta última es la única forma de acceso que tenemos a ella. Lo anterior reúne dos puntos por los que la oposición entre cronología natural y tiempo histórico no parece ser absoluta: nuestro conocimiento sobre los fenómenos astronómicos está mediado por un saber científico y el avance de la técnica evidencia una progresiva influencia del hombre en el comportamiento de los astros.

Para terminar, podríamos decir que una de las grandes ventajas de este texto introductorio es la de volver sobre puntos neurálgicos de la Historik koselleckiana, que señala no solo la relevancia de una teoría de la historia que acompañe una investigación centrada en la facticidad, sino las condiciones de posibilidad de esta última. Es decir, se trata de una mirada que va más allá de lo que tuvo lugar en la historia, en tanto se pregunta qué pudo, qué puede y qué podrá tener lugar. Tiene la potencia de ser predictiva en el sentido de que muestra qué puede suceder pero sin que eso signifique que esos contenidos se vuelvan necesarios, inevitables o fatídicos. La productividad política de una tesis tal apunta, en cambio, a la elaboración de diagnósticos históricos que nos ayuden a tratar con las posibilidades de aquello que puede ser posible, a comprender su emergencia como el resultado de una convergencia de estratos temporales que combinen adecuadamente unicidad y repetición. En fin, el mérito de la traducción, a la que acompaña este comentario, reside no solo en seguir con la tarea de abrir el acceso a la obra de Koselleck al mundo hispanoparlante, sino además en apostar por un sector poco visitado en el ámbito latinoamericano, que, en general, se concentra en su historia conceptual y comete el error de dejar de lado su teoría de los tiempos históricos. Acaso dicha tendencia y la mala suerte editorial de los escritos de Koselleck en la academia local puedan tomar otro curso con la difusión de trabajos que lo conectan con discusiones propias de la filosofía de la historia y dignas de ser investigadas, si se quiere responder a una visión conjunta de su legado.

\footnotetext{
21 “[...] como si no tuviese que regirse la Cronología por la Historia, sino a la inversa, la Historia por la Cronología”. Kant, Antropología, p.131.
} 